\title{
Vitamin K1 (phylloquinone) and K2 (menaquinone-4) supplementation improves bone formation in a high-fat diet-induced obese mice
}

\author{
Misung Kim, Woori Na and Cheongmin Sohn* \\ Department of Food and Nutrition, Wonkwang University, Iksandae-ro, Iksan, Jeonbuk 570-749, Korea
}

(Received 5 March, 2013; Accepted 1 May, 2013; Published online 24 July, 2013)

\begin{abstract}
Several reports suggest that obesity is a risk factor for osteoporosis. Vitamin $K$ plays an important role in improving bone metabolism. This study examined the effects of vitamin $\mathrm{K} 1$ and vitamin $\mathrm{K} 2$ supplementation on the biochemical markers of bone turnover and morphological microstructure of the bones by using an obese mouse model. Four-week-old C57BL/6J male mice were fed a $10 \%$ fat normal diet group or a $45 \%$ kcal high-fat diet group, with or without $200 \mathrm{mg} / \mathbf{1 0 0 0} \mathrm{g}$ vitamin K1 (Normal diet + $\mathrm{K} 1$, high-fat diet $+\mathrm{K} 1$ ) and $200 \mathrm{mg} / 1000 \mathrm{~g}$ vitamin $\mathrm{K} 2$ (Normal diet + K2, high-fat diet + K2) for 12 weeks.

Serum levels of osteocalcin were higher in the high-fat diet + K2 group than in the high-fat diet group. Serum OPG level of the high-fat diet group, high-fat diet + K1 group, and high-fat diet + $\mathrm{K} 2$ group was $2.31 \pm 0.31 \mathrm{ng} / \mathrm{ml}, 2.35 \pm 0.12 \mathrm{ng} / \mathrm{ml}$, and $2.90 \pm 0.11$ $\mathrm{ng} / \mathrm{ml}$, respectively. Serum level of RANKL in the high-fat diet group was significantly higher than that in the high-fat diet + K1 group and high-fat diet + K2 group $(p<0.05)$. Vitamin $K$ supplementation seems to tend to prevent bone loss in high-fat diet induced obese state. These findings suggest that vitamin $K$ supplementation reversed the high fat diet induced bone deterioration by modulating osteoblast and osteoclast activities and prevent bone loss in a high-fat diet-induced obese mice.
\end{abstract}

Key Words: vitamin K, obesity, bone density, osteoblast, osteoclast

I $\mathrm{n}$ view of the recent increase in the aged population in Korea, emphasis has been placed on the prevention of and treatment for chronic diseases. ${ }^{(1,2)}$ Obesity has been studied as a factor that causes chronic diseases such as diabetes, ${ }^{(3)}$ osteoarthritis, ${ }^{(4)}$ hypertension, and cardiovascular disease, ${ }^{(5)}$ and thus, it requires management. The prevalence of osteoporosis due to aging has also been increasing. Generally, bone density is known to be proportional to the body mass index (BMI); the higher the BMI, the higher the bone density, but recent studies have reported lower bone density in the obese population than that in non-obese people. ${ }^{(6-12)}$ Therefore, prevention and treatment for obese people with osteoporosis are needed.

In bone metabolism, balanced bone formation by osteoblasts and bone resorption by osteoclasts maintains homeostasis. Imbalance in bone formation and resorption causes changes that lead to skeleton loss, osteoporosis, and osteomalacia. ${ }^{(13,14)}$ Among the many indices related to bone metabolism, type I collagen Ctelopeptide (CTx) has been reported as a bone resorption marker, osteocalcin (OC) as a bone formation marker (in blood), and receptor activator of $\mathrm{NF}-\kappa \mathrm{B}$ ligand (RANKL) and osteoprotegerin
(OPG) as markers related to the production and activity of osteoblasts and osteoclasts.

Vitamin $\mathrm{K}$ is related to blood coagulation, assisting the promotion of OC carboxylation of $\gamma$-glutamic acid, which is produced by osteoblasts, and aiding in bone formation by coupling carboxylated OC with phosphine. ${ }^{(15)}$ Many studies have demonstrated that low intake of vitamin $\mathrm{K}$ decreases bone density, and that this is a factor that increases osteoporosis and bone fracture. ${ }^{(16)}$ In the study by Booth et al., ${ }^{(17)}$ low intake of vitamin $\mathrm{K} 1$ led to low bone density, and was a factor for increased risk of bone fracture. When vitamin $\mathrm{K} 1$ was administered to human bone marrow culture, osteoclast formation was inhibited. ${ }^{(13)}$ After administering vitamin $\mathrm{K} 2$ to osteoblasts, real-time gene expression analysis found that the $O C, O P G$, and $R A N K L$ genes were expressed, demonstrating that vitamin $\mathrm{K} 2$ has an influence on osteoblasts and osteoclasts. ${ }^{(18)}$ In addition, vitamin K2 supplementation in patients with osteoporosis necessitated by the administration of glucocorticoids inhibited OPG decrease, and had effects of bone loss prevention. ${ }^{(19)}$ Vitamin K2 supplementation in patients with rheumatoid arthritis accompanied with osteoporosis decreased RANKL levels and inhibited osteoclast activation. ${ }^{(20)}$ Therefore, vitamin K affects bone condition both in healthy adults and in patients with specific diseases.

Therefore, this study attempted to describe the bone metabolism indices related to osteoblasts and osteoclasts and the morphology of bone microstructure through vitamin $\mathrm{K} 1$ and $\mathrm{K} 2$ supplementation in an obese mouse model under a high-fat diet. The C57BL/6 J mouse is easy to become obese with high-fat diet. ${ }^{(21)}$

\section{Materials and Methods}

Animals and diets. Forty-two male, 4-week-old C57BL/6J mice were purchased from Central Lab Animal Inc., Korea. During the experiment, an automated constant-temperature humidity system was used to maintain a temperature of $23^{\circ} \mathrm{C} \pm 2{ }^{\circ} \mathrm{C}$ and humidity of $60 \% \pm 3 \%$ for the animals. The animals were provided with feed and drink ad libitum. This animal experiment was approved by the Won Kwang University Institutional Animal Care and Use Committees. For environmental adaptation, the animals had 1 week of circulation, and then were provided with the experimental diet after being randomly divided into 6 groups ( 7 animals in each group; randomized block design). The AIN-93G diets consisted of a normal diet (N), normal

To whom correspondence should be addressed.

E-mail: ccha@wku.ac.kr 
Table 1. Composition of experimental diet ( $\mathrm{g} / \mathrm{kg}$ diet)

\begin{tabular}{|c|c|c|c|c|c|c|}
\hline Formula & $\mathrm{N}$ & $\mathrm{N}-\mathrm{K} 1$ & $\mathrm{~N}-\mathrm{K} 2$ & $\mathrm{HF}$ & HF-K1 & HF-K2 \\
\hline Protein (g \%/kcal \%) & $20 / 20$ & $20 / 20$ & $20 / 20$ & $24 / 20$ & $24 / 20$ & $24 / 20$ \\
\hline Carbohydrate (g \%/kcal \%) & $64 / 64$ & $64 / 64$ & $64 / 64$ & $44 / 35$ & $44 / 35$ & $44 / 35$ \\
\hline Fat $(g \% / k c a l \%)$ & $1 / 4$ & $1 / 4$ & $1 / 4$ & $24 / 45$ & $24 / 45$ & $24 / 45$ \\
\hline Casein, lactic ${ }^{1)}$ & 200 & 200 & 200 & 200 & 200 & 200 \\
\hline L-Cystine ${ }^{2)}$ & 3 & 3 & 3 & 3 & 3 & 3 \\
\hline Corn starch ${ }^{3)}$ & 397.486 & 397.486 & 397.486 & 105 & 105 & 105 \\
\hline Sucrose $\mathrm{e}^{4)}$ & 100 & 100 & 100 & 100 & 100 & 100 \\
\hline Dextrose ${ }^{5)}$ & 132 & 132 & 132 & 132 & 132 & 132 \\
\hline Cellulose $^{6)}$ & 50 & 50 & 50 & 50 & 50 & 50 \\
\hline Soybean oil7) & 70 & 70 & 70 & 25 & 25 & 25 \\
\hline $\operatorname{Lard}^{8)}$ & 0 & 0 & 0 & 175 & 175 & 175 \\
\hline t-Butylhydroquinone ${ }^{9)}$ & 0.014 & 0.014 & 0.014 & 0.014 & 0.014 & 0.014 \\
\hline AIN-93G mineral mix ${ }^{10)}$ & 35 & 35 & 35 & 35 & 35 & 35 \\
\hline AIN-93 vitamin mix ${ }^{11)}$ & 10 & 10 & 10 & 10 & 10 & 10 \\
\hline Choline bitartrate ${ }^{12)}$ & 2.5 & 2.5 & 2.5 & 2.5 & 2.5 & 2.5 \\
\hline Vitamin $\mathrm{K} 1^{13)}$ & & 0.2 & & & 0.2 & \\
\hline Vitamin $\mathrm{K} 2^{14)}$ & & & 0.2 & & & 0.2 \\
\hline
\end{tabular}

1) Casein, Harlan Teklad. USA; 2) L-Cystein, Wako. Japen; 3) Corn starch, Daejung. Korea; 4) Sucrose, Daejung. Korea; 5) Dextrose, Wako. Japen; 6) Cellulose, JRS. Germany; 7) Soybean oil, daesang. Korea; 8) Lard, wellga. Korea; 9) t-Butylhydroquinone, Wako. Japen; 10) AIN-93G-MX, Harlan Teklad. USA; 11) AIN-93G-VX, Harlan Teklad. USA; 12) Choline Bitartrate, Wako. Japen; 13) Vitamin K1, Sigma Chemical. USA; 14) Vitamin K2, Sigma Chemical. USA.

diet + vitamin $\mathrm{K} 1(\mathrm{~N}-\mathrm{K} 1)$, normal diet + vitamin $\mathrm{K} 2(\mathrm{~N}-\mathrm{K} 2), 45 \%$ high-fat diet (HF), 45\% high-fat diet + vitamin K1 (HF-K1), and a $45 \%$ high-fat diet + vitamin K2 (HF-K2). The vitamin K1 (Sigma, St. Louis, MO) and vitamin K2 (Sigma) contents were $200 \mathrm{mg} /$ $1,000 \mathrm{~g}$, and the diet was provided in pellet form. The details are listed in Table 1. Food intake amount was measured every other day. Body weight was measured once a week, and the food efficiency ratio (FER) was calculated by dividing the increased body weight from dayl to the final day by the food intake amount during the experiment period. For fat amount measurement, the epididymal fat, perirenal fat, and retroperitoneal fat were extracted from dead animal subjects, were washed with $0.9 \% \mathrm{NaCl}$, dried by filter paper, and then were weighed.

Biochemical analysis. After 12 weeks, the animals were fasted for $12 \mathrm{~h}$, sacrificed with ether, and then their blood was collected from the aorta and orbital veins. The blood samples were centrifuged at $3,000 \mathrm{rpm}$ for $15 \mathrm{~min}$ and stored at $-70^{\circ} \mathrm{C}$ until analysis. OPG (Immundiagnostik, Bensheim, Germany), RANKL (Immundiagnostik), CTx (RatLaps, Herlev, Denmark), and OC (Cusabio, Wuhan, China) were measured with an ELISA reader (Molecular Devices, Sunnyvale, CA) according to the kit.

Bone measurement. After the experimental diet, the femur was removed and stored in formalin to acquire bone micro-images through high-resolution 3-dimensional (3D) micro focus computed tomography (micro-CT; SkyScan 1172TM, SkyScan, Kontich, Belgium). The Martín-Badosa et al. ${ }^{(22)}$ and Fujikawa et al. ${ }^{(23)}$ analyses were used. Micro-images were reconstructed in gray-scale using Necron ver. 1.10 (SkyScan), and the reconstructed 2D image was reconstructed into a 3D model using CT An software (SkyScan). The CT An software analyzed the measured femoral bone by establishing the region of interest at $2.35 \mathrm{~mm}$ from the cartilage above the growth plate. The measurements included bone mineral density (BMD), bone volume (BV), which is the morphology of the bone microstructure, bone-specific surface (BS/BV), percent bone volume with in the volume of interest (BV/TV), trabecular thickness (Tb.Th), trabecular number (Tb.N), trabecular spacing (Tb.Sp), structure model index (SMI), and connectivity density.

Statistical analysis. SPSS ver. 19.0 was used for statistical analysis. The results are presented as the mean and standard error (SEM). The Mann-Whitney $U$ test was used for the differ- ence between the HF and $\mathrm{N}$ groups, one-way ANOVA was used for the difference between the N, N-K1 and N-K2 groups, and the HF, HF-K1 and HF-K2 groups, and the Duncan test was used for post-hoc comparison between the groups, respectively. The significance was set at $p<0.05$.

\section{Results}

Lab animal body weights and diet efficiency. The initial and final body weights and diet efficiency of the lab animals are presented in Table 2 . The initial and final body weight difference in each group was not significant, but the final weight in the HF$\mathrm{K} 2$ group was lower. Epididymal fat, compared to the normal diet group $1.69 \pm 0.08 \mathrm{~g}$, the HF group resulted higher $2.04 \pm 0.13 \mathrm{~g}$ $(p<0.05)$, retroperitoneal fat was also higher in high-fat diet group $0.58 \pm 0.01 \mathrm{~g}$ compared to the normal diet group $0.05 \pm 0.04 \mathrm{~g}$ $(p<0.05)$. The total fat amount including epididymal fat, perirenal fat, and retroperitoneal fat was significantly higher in high-fat diet $2.89 \pm 0.15 \mathrm{~g}$ compared to the normal diet group $2.43 \pm 0.13 \mathrm{~g}$ $(p<0.05)$. Epididymal fat was significantly different between the HF-K1 group $1.58 \pm 0.15 \mathrm{~g}$ and HF-K2 group $1.36 \pm 0.23 \mathrm{~g}$ compared to the HF group $(p<0.05)$. Perirenal fat was lower in the HF-K1 group $0.22 \pm 0.07 \mathrm{~g}$ and HF-K2 group $0.16 \pm 0.07 \mathrm{~g}$ compared to the HF group $(p<0.05)$. Total fat amount was significantly lower in the HF-K1 group and HF-K2 group than the HF group $(p<0.05)$. Total fat was no significantly different between the N-K1 group $2.26 \pm 0.25 \mathrm{~g}$ and N-K2 group $2.20 \pm 0.21 \mathrm{~g}$ compared to the $\mathrm{N}$ group. Total food intake amount during the experiment was $239.85 \pm 9.00 \mathrm{~g}$ in normal diet group, $180.51 \pm 3.94 \mathrm{~g}$ in high-fat diet group $(p<0.001), 248.31 \pm 1.00 \mathrm{~g}$ in the $\mathrm{N}+\mathrm{K} 1$ group, $223.95 \pm 10.56 \mathrm{~g}$ in the $\mathrm{N}+\mathrm{K} 2$ group and $153.60 \pm 9.17 \mathrm{~g}$ in the HF-K1 group, $155.72 \pm 14.34 \mathrm{~g}$ in the HF-K2 group.

Diet efficiency was lower in the HF group than that in the $\mathrm{N}$ group $(p<0.01)$, but no difference was found between the HF group and the HF-K1 and HF-K2 groups.

Bone metabolism index analysis. The results of the bone metabolism index analysis are shown in Table 3. For the statistical analysis on bone metabolism marker, the difference between normal diet and high-fat diet was analyzed, and then the vitamin $\mathrm{K} 1$ and K2 supplementation groups were compared with high-fat diet group. 
Table 2. Lab animal body weights and diet efficiency

\begin{tabular}{|c|c|c|c|c|c|c|}
\hline & $\mathrm{N}$ & $\mathrm{N}-\mathrm{K} 1$ & $\mathrm{~N}-\mathrm{K} 2$ & $\mathrm{HF}$ & HF-K1 & HF-K2 \\
\hline Initial body weight (g) & $20.69 \pm 0.35$ & $20.46 \pm 0.35$ & $19.69 \pm 0.29$ & $19.69 \pm 0.33$ & $19.57 \pm 0.29$ & $19.50 \pm 1.11$ \\
\hline Final body weight (g) & $35.34 \pm 0.64$ & $34.97 \pm 0.92$ & $35.39 \pm 0.73$ & $37.31 \pm 0.34$ & $35.24 \pm 2.50$ & $33.54 \pm 1.57$ \\
\hline Epididymal fat (g) & $1.69 \pm 0.08$ & $1.49 \pm 0.15$ & $1.50 \pm 0.14$ & $2.04 \pm 0.13^{* b}$ & $1.58 \pm 0.15^{\mathrm{ab}}$ & $1.36 \pm 0.23^{\# a}$ \\
\hline Peri-renal fat (g) & $0.24 \pm 0.02$ & $0.32 \pm 0.12$ & $0.22 \pm 0.02$ & $0.26 \pm 0.02^{b}$ & $0.22 \pm 0.07^{a b}$ & $0.16 \pm 0.07^{\# a}$ \\
\hline Retroperitoneal fat (g) & $0.50 \pm 0.04$ & $0.45 \pm 0.03$ & $0.49 \pm 0.05$ & $0.58 \pm 0.01 *$ & $0.49 \pm 0.09$ & $0.44 \pm 0.04$ \\
\hline Total fat $(\mathrm{g})$ & $2.43 \pm 0.13$ & $2.26 \pm 0.25$ & $2.20 \pm 0.21$ & $2.89 \pm 0.15^{\star b}$ & $2.30 \pm 0.20^{\mathrm{ab}}$ & $1.95 \pm 0.33^{\# a}$ \\
\hline Food intake (g) & $239.85 \pm 9.00$ & $248.31 \pm 0.60$ & $223.95 \pm 10.55$ & $180.51 \pm 3.94 * * *$ & $153.60 \pm 9.17$ & $155.72 \pm 14.34$ \\
\hline FER & $0.06 \pm 0.00$ & $0.06 \pm 0.00$ & $0.07 \pm 0.00$ & $0.09 \pm 0.01 * *$ & $0.10 \pm 0.01$ & $0.09 \pm 0.12$ \\
\hline
\end{tabular}

Values represent the means \pm SEM $(n=7)$; Values are significantly different between the N and HF groups at * $p<0.05, * * p<0.01, * * * p<0.001$ according to Mann-Whitney $U$ test; The ANOVA test and data with different superscript letters within the same row are significantly different by Duncan test. $\# p<0.05$.

Table 3. Bone metabolism index analysis

\begin{tabular}{|c|c|c|c|c|c|c|}
\hline & $\mathrm{N}$ & $\mathrm{N}-\mathrm{K} 1$ & $\mathrm{~N}-\mathrm{K} 2$ & $\mathrm{HF}$ & HF-K1 & HF-K2 \\
\hline Osteocalcin (ng/ml) & $57.60 \pm 4.17$ & $53.64 \pm 5.38$ & $59.67 \pm 5.11$ & $41.84 \pm 1.54 *$ & $52.27 \pm 5.54$ & $51.02 \pm 7.34$ \\
\hline CTx $(n g / m l)$ & $24.52 \pm 1.80$ & $28.15 \pm 1.37$ & $29.56 \pm 2.11$ & $30.88 \pm 2.14^{*}$ & $29.60 \pm 1.83$ & $27.38 \pm 1.63$ \\
\hline OPG (ng/ml) & $1.47 \pm 0.42$ & $1.67 \pm 0.27$ & $1.45 \pm 0.20$ & $2.31 \pm 0.31$ & $2.35 \pm 0.12$ & $2.90 \pm 0.11$ \\
\hline RANKL (ng/ml) & $0.30 \pm 0.03$ & $0.32 \pm 0.04$ & $0.29 \pm 0.03$ & $0.40 \pm 0.06^{b}$ & $0.26 \pm 0.02^{a}$ & $0.21 \pm 0.03^{\# a}$ \\
\hline RANKL/OPG & $0.32 \pm 0.08$ & $0.22 \pm 0.03$ & $0.22 \pm 0.04$ & $0.21 \pm 0.06^{b}$ & $0.12 \pm 0.01^{\mathrm{ab}}$ & $0.07 \pm 0.01^{\# \# \mathrm{a}}$ \\
\hline
\end{tabular}

Values represent the means \pm SEM $(n=7)$; Values are significantly different between the N and HF groups at * $p<0.05$ according to Mann-Whitney $U$ test; The ANOVA test and data with different superscript letters within the same row are significantly different by Duncan test. \# $p<0.05$; \#\# $p<0.01$.

Among the biochemical markers of bone metabolism, the bone formation index, OC, was lower in the HF group (41.84 \pm $1.54 \mathrm{ng} / \mathrm{ml})$ than the $\mathrm{N}$ group $(57.60 \pm 4.17 \mathrm{ng} / \mathrm{ml} ; p<0.05)$, and the bone resorption marker CTx was higher in the HF group $(30.88 \pm 2.14 \mathrm{ng} / \mathrm{ml})$ than in the $\mathrm{N}$ group $(24.52 \pm 1.80 \mathrm{ng} / \mathrm{ml}$; $p<0.05)$. OC levels in the N-K1 group, N-K2 group and HF-K1, HF-K2 groups were $53.60 \pm 5.38 \mathrm{ng} / \mathrm{ml}, 59.67 \pm 5.1138 \mathrm{ng} / \mathrm{ml}$ and $52.27 \pm 5.54 \mathrm{ng} / \mathrm{ml}, 51.02 \pm 7.34 \mathrm{ng} / \mathrm{ml}$, respectively. CTx levels in the N-K1 group, N-K2 group and HF-K1, HF-K2 groups were $28.15 \pm 1.37 \mathrm{ng} / \mathrm{ml}, 29.56 \pm 2.11 \mathrm{ng} / \mathrm{ml}$ and $29.60 \pm 1.83$ $\mathrm{ng} / \mathrm{ml}, 27.38 \pm 1.63 \mathrm{ng} / \mathrm{ml}$, respectively. There was $2.31 \pm 0.31$ $\mathrm{ng} / \mathrm{ml}$ of the osteoclast inhibitor, OPG, in the HF group, $2.35 \pm$ $0.12 \mathrm{ng} / \mathrm{ml} \mathrm{OPG}$ in the HF-K1 group, and $2.90 \pm 0.11 \mathrm{ng} / \mathrm{ml} \mathrm{OPG}$ in the HF-K2 group, demonstrating that the OPG concentration was increased. The levels of RANKL, which is related to osteoclast formation, were $0.40 \pm 0.06 \mathrm{ng} / \mathrm{ml}, 0.26 \pm 0.02 \mathrm{ng} / \mathrm{ml}$, and $0.21 \pm 0.11 \mathrm{ng} / \mathrm{ml}$ in the HF group, HF-K1group, and HF-K2 group, respectively $(p<0.05)$. The ratio of bone RANKL/OPG, was $0.32 \pm 0.08$ in the $\mathrm{N}$ group, $0.22 \pm 0.03$ in the N-K1 group, $0.22 \pm 0.04$ in the N-K2 group and $0.21 \pm 0.06$ in the HF group, $0.12 \pm 0.01$ in the HF-K1 group, $0.07 \pm 0.01$ in the HF-K2 group, demonstrating that high fat diet with vitamin $\mathrm{K}$ supplementation significantly suppressed the activities of bone resorption by osteoclast $(p<0.01)$.

Morphologic analysis of bone density and structure.

Two-dimensional image analysis and 3D cross-sectional and lateral analyses were performed using images of the bone microstructure. We determined that the HF-K1 and HF-K2 groups had less bone loss compared to that in the HF group (Fig. 1). Based on the image analysis, the microstructural bone analysis results are shown in Table 4. Bone density in the HF group was low $(0.22 \pm 0.00)$ as compared to that in the $\mathrm{N}$ group $(0.24 \pm 0.01$; $p<0.05)$, and the bone density in the HF-K1 and HF-K2 groups increased to $0.23 \pm 0.00$ and $0.24 \pm 0.00$, respectively, due to the vitamin $\mathrm{K}$ supplementation. No significance was found in the Tb.N, although the Tb.N in the HF-K1 and HF-K2 groups increased to $1.05 \pm 0.04$ and $1.10 \pm 0.07$, respectively, compared to $1.03 \pm 0.07$ in the HF group.

\section{Discussion}

Previous studies have reported conflicting results that vitamin $\mathrm{K}$ supplementation induces an increase or no effect in the bone density in patients with osteoporosis. ${ }^{(24,25)}$ Simultaneous bone morphologic analysis and biochemical tests need to be conducted to determine whether the intake of vitamin $\mathrm{K}$ influences on bone metabolism. Therefore, this study performed to determined effects of vitamin $\mathrm{K} 1$ and $\mathrm{K} 2$ supplementation on bone metabolism, density, and microstructure in a high-fat diet-induced obese mice.

Although there was no body weight difference between normal diet group and high-fat diet group in this study, the epididymal fat, perirenal fat, and retroperitoneal fat accumulation were higher in high-fat diet group than the normal diet group. The total fat amount of these three areas were also higher in the high-fat diet group. Body weight includes the weight of fat, muscle, and other organs. The weight of fat is lighter than muscle or other organs although its volume is bigger; it was lower in high-fat diet animals in this study. Body weight and body fat amount can be used as the obesity marker, and the increase in fat due to high-fat diet may have induced obesity in this study.

Osteoblasts and fat cell derive from mesenchymal stem cell, and they decrease as fat cells increase, causing bone loss. ${ }^{(26)}$ Recently, a metabolic correlation between obesity and bone density was reported. This was also found in the study of Kim et al. ${ }^{(27)}$, which focused on the bone density and bone metabolism of the obesityinduced mouse, and whose results revealed lower bone density in obese mice caused by a high-fat diet.

Vitamin $\mathrm{K}$ is an accessory factor that affects bone formation by promoting the carboxylation of $\gamma$-glutamic acid in osteocalcin, which is generated in osteoblasts. In this study, osteocalcin, which is the bone formation marker, was lower in high-fat diet group than the normal diet group, and CTx, which is the bone resorption marker, was higher in high-fat diet group than the normal diet group. This showed that obesity by high-fat diet decreases bone formation, and increases bone resorption. The bone formation marker ${ }^{(28)}$ OC has been reported to increase with the intake of vitamin $\mathrm{K}$. In this study, OC level of HF groups which were 


\begin{tabular}{|c|c|c|c|c|c|c|}
\hline & $\mathrm{N}$ & $\mathrm{N}-\mathrm{K} 1$ & $\mathrm{~N}-\mathrm{K} 2$ & $\mathrm{HF}$ & HF-K1 & HF-K2 \\
\hline \multicolumn{7}{|l|}{ 2D } \\
\hline \multicolumn{7}{|l|}{ Images } \\
\hline \multicolumn{7}{|l|}{$3 \mathrm{D}$} \\
\hline \multicolumn{7}{|c|}{ Cross-section } \\
\hline \multicolumn{7}{|l|}{$3 \mathrm{D}$} \\
\hline Images & & & & & & \\
\hline
\end{tabular}

Fig. 1. Femur morphologic analysis of bone density and structure. Three-dimensional imaging analysis was performed by microcomputed tomography. The reconstructed 2D image was reconstructed into a 3D model using CT An software (SkyScan, Kontich, Belgium).

Table 4. Bone density and bone microstructure morphology

\begin{tabular}{|c|c|c|c|c|c|c|}
\hline & $\mathrm{N}$ & $\mathrm{N}-\mathrm{K} 1$ & $\mathrm{~N}-\mathrm{K} 2$ & $\mathrm{HF}$ & HF-K1 & HF-K2 \\
\hline BMD & $0.24 \pm 0.00$ & $0.25 \pm 0.00$ & $0.25 \pm 0.01$ & $0.22 \pm 0.00$ * & $0.23 \pm 0.00$ & $0.24 \pm 0.00$ \\
\hline $\mathrm{BV}\left(\mathrm{mm}^{3}\right)$ & $1.21 \pm 0.09$ & $1.47 \pm 0.08$ & $1.34 \pm 0.11$ & $0.97 \pm 0.08^{*}$ & $0.98 \pm 0.05$ & $1.09 \pm 0.10$ \\
\hline BV/TV (\%) & $10.3 \pm 0.67$ & $11.71 \pm 0.53$ & $11.00 \pm 0.85$ & $8.37 \pm 0.64$ & $8.29 \pm 0.41$ & $9.35 \pm 0.85$ \\
\hline Tb.Th (mm) & $0.08 \pm 0.00$ & $0.09 \pm 0.00$ & $0.08 \pm 0.00$ & $0.08 \pm 0.00$ & $0.08 \pm 0.00$ & $0.08 \pm 0.00$ \\
\hline Tb. N (1/mm) & $1.24 \pm 0.08$ & $1.37 \pm 0.05$ & $1.29 \pm 0.10$ & $1.03 \pm 0.07$ & $1.05 \pm 0.04$ & $1.10 \pm 0.07$ \\
\hline Tb.Sp (mm) & $0.43 \pm 0.01$ & $0.43 \pm 0.01$ & $0.41 \pm 0.01$ & $0.45 \pm 0.01$ & $0.44 \pm 0.01$ & $0.43 \pm 0.01$ \\
\hline
\end{tabular}

Values represent the means \pm SEM $(n=7)$; Values are significantly different between the $\mathrm{N}$ and HF groups at * $p<0.05$ according to Mann-Whitney $U$ test.

supplemented with vitamin $\mathrm{K} 1$ or $\mathrm{K} 2$, was higher than that in the HF diet-only group. Consequentially, it was demonstrated in the vitamin $\mathrm{K}$-supplemented HF group that the intake of vitamin $\mathrm{K}$ had an influence on bone formation compared to the $\mathrm{N}$ group, and that the decrease in OC due to a high-fat diet can be recovered with vitamin $\mathrm{K}$ supplementation. CTx, a bone resorption marker, was higher in the HF group than in the $\mathrm{N}$ group. This result was similar to the study by Patsch et al., ${ }^{(29)}$ which reported higher CTx values in the high-fat diet group than in the low-fat diet group. In this study, CTx was lower in the vitamin K-supplemented HF groups than the HF diet-only group. As the final body weights in the vitamin K-supplemented groups were lower, the intake of vitamin $\mathrm{K}$ evidently decreased the excessive increase in body weight and had an influence on bone metabolism. Therefore, vitamin K1 and K2 supplementation decreases the bone resorption index and increases the bone formation index, balancing bone metabolism, and is thus considered to prevent bone loss.

OPG is a substance that inhibits osteoclast differentiation by interacting with RANKL. A study reported that an increase in OPG increases bone density in men, ${ }^{(30)}$ and an animal study reported an increase in trabecular bone when OPG was administered to mice. ${ }^{(31)}$ Cellular experiments have also reported an influence of vitamin $\mathrm{K} 2$ on osteoblasts and osteoclasts. ${ }^{(13)}$
Koshihara et al. ${ }^{(13)}$, demonstrated that vitamin $\mathrm{K} 1$ and $\mathrm{K} 2$ treatment decreased the expression of RANKL and enhanced the expression of OPG in the stromal cells, and they conclude that Vitamin K might stimulate osteoblastogenesis in bone marrow cells, controlling osteoclastogenesis through the expression of RANKL. In our study, OPG increased in the group supplemented with vitamin $\mathrm{K} 2$, while RANKL decreased in the same group. Based on this finding, OPG and RANKL, which are involved in osteoclast activity, are considered to be influenced by vitamin $\mathrm{K}$ in mice that are obese due to a high-fat diet.

Also, the receptor activator of nuclear factor- $\kappa \mathrm{B}$ ligand (RANKL), which is a metabolite inside an osteoblast, decreased when vitamin $\mathrm{K}$ was supplemented in high-fat diet group, and OPG, which inhibits RANKL and osteoclast differentiation, also decreased after vitamin supplementation. This showed that vitamin $\mathrm{K}$ supplementation changes the balance of bone formation and bone resorption in bone metabolism, and leads to bone density increase as a result. However, the results of osteocalcin and CTx, which showed increased osteocalcin and decreased CTx after vitamin K supplementation, were not statistically significant. This might be due to small sample size.

The results of the bone density analysis revealed an increase with the vitamin $\mathrm{K} 1$ and $\mathrm{K} 2$ supplementation in high-fat diets. 
Studies on the relationship between bone density and vitamin $\mathrm{K}$ generally have used dual-energy x-ray absorptiometry or ultrasonic densitometry, ${ }^{(32)}$ but this study used high-resolution 3D micro-CT to analyze the morphologic microstructure of trabecular bone. In the study by Fujikawa et al., ${ }^{(24)}$ the Tb.N increased when vitamin $\mathrm{K} 2$ and calcium were fed to ovariectomized mice, and the Tb.Sp decreased. Yamaguchi et al., ${ }^{(33)}$ also fed vitamin K2 to ovariectomized rats, and reported that it prevented bone loss. These two studies used osteoporosis-induced animals, and the methods differed from those in this study, in which obesityinduced mice were fed vitamin K supplements. In this study, even though there was no significantly statistical difference in the microstructure analysis between the groups, but BV, Tb.N, and Tb.Sp were seemed to be better in the vitamin K2-supplemented group than those in the HF group, indicating that vitamin K2 may play a role in protecting the structures of trabecular bone.

This study determined that a high-fat diet induces a decrease in bone density and an increase osteoclast activity and decrease osteoblast activity in bone metabolism indices.

The effects of vitamin $\mathrm{K} 1$ and $\mathrm{K} 2$ supplementation in normal diet on bone metabolism were not statistically significant. However, vitamin K1 and K2 supplementation in a high-fat diet could prevent a decrease in bone density, and vitamin $\mathrm{K} 2$ had a greater effect on this parameter. Therefore, vitamin K2 increases OPG, a marker related to bone density and the metabolism of osteoclasts and osteoblasts, and it decreases RANKL, and thus has an influence on bone metabolism. This study has showed the effects of vitamin $\mathrm{K}$ on bone density and metabolism in animals, but further studies are needed to determine whether the same holds true for obese humans. Future studies would need to

\section{References}

1 Wolff JL, Starfield B, Anderson G. Prevalence, expenditures, and complications of multiple chronic conditions in the elderly. Arch Intern Med 2002; 162: 2269-2276.

2 Statistics Korea. Household projections for Korea: 2005-2030, 2012.

3 Neeland IJ, Turer AT, Ayers CR, et al. Dysfunctional adiposity and the risk of prediabetes and type 2 diabetes in obese adults. JAMA 2012; 308: 1150 1159 .

4 Felson DT, Zhang Y, Anthony JM, Naimark A, Anderson JJ. Weight loss reduces the risk for symptomatic knee osteoarthritis in women. The Framingham Study. Ann Intern Med 1992; 116: 535-539.

5 Lavie CJ, Messerli FH. Cardiovascular adaptation to obesity and hypertension. Chest 1986; 90: 275-279.

6 Joakimsen RM, Fønnebø V, Magnus JH, Tollan A, Sogaard AJ. The Tromso Study: body height, body mass index and fractures. Osteoporos Int 1998; 8: 436-442.

7 Johnell O, Gullberg B, Kanis JA, et al. Risk factors for hip fracture in European women: the MEDOS Study. Mediterranean Osteoporosis Study. $J$ Bone Miner Res 1995; 10: 1802-1815.

8 Fujiwara S, Kasagi F, Yamada M, Kodama K. Risk factors for hip fracture in a Japanese cohort. J Bone Miner Res 1997; 12: 998-1004.

9 Kim KC, Shin DH, Lee SY, Im JA, Lee DC. Relation between obesity and bone mineral density and vertebral fractures in Korean postmenopausal women. Yonsei Med J 2010; 51: 857-863.

10 Lee JS, Kawakubo K, Sato H, Kobayashi Y, Haruna Y. Relationship between total and regional bone mineral density and menopausal state, body composition and life style factors in overweight Japanese women. Int $J$ Obes Relat Metab Disord 2001; 25: 880-886.

11 Tóth E, Ferenc V, Mészáros S, Csupor E, Horváth C. Effects of body mass index on bone mineral density in men. Orv Hetil 2005; 146: 1489-1493.

12 Hsu YH, Venners SA, Terwedow HA, et al. Relation of body composition, fat mass, and serum lipids to osteoporotic fractures and bone mineral density in Chinese men and women. Am J Clin Nutr 2006; 83: 146-154.

13 Koshihara Y, Hoshi K, Okawara R, Ishibashi H, Yamamoto S. Vitamin K stimulates osteoblastogenesis and inhibits osteoclastogenesis in human bone marrow cell culture. J Endocrinol 2003; 176: 339-348.

14 Bessette L, Jean S, Lapointe-Garant MP, et al. Direct medical costs attribut- perform bone measurement and biochemical examinations on the bone microstructures and metabolism in humans.

\section{Acknowledgments}

This research was supported by Basic Science Research Program through the National Research Foundation of Korea (NRF) funded by the Ministry of Education, Science and Technology, (project no. : 2012R1A1A3012499).

\section{Abbreviations}

BMD bone mineral density

BMI body mass index

$\mathrm{BS} / \mathrm{BV}$ bone specific surface

BV bone volume

$\mathrm{BV} / \mathrm{TV}$ percent bone volume with in the volume of interest

CTx type I collagen C-telopeptide

FER food efficiency ratio

OC osteocalcin

OPG osteoprotegerin

RANKL receptor activator of $N F-\kappa B$ ligand

SMI structure model index

Tb.N trabecular number

Tb.Sp trabecular spacing

Tb.Th trabecular thickness

\section{Conflict of Interest}

No potential conflicts of interest were disclosed.

able to peripheral fractures in Canadian post-menopausal women. Osteoporos Int 2012; 23: 1757-1768.

15 Berkner KL. The vitamin K-dependent carboxylase. Annu Rev Nutr 2005; 25: $127-149$

16 Apalset EM, Gjesdal CG, Eide GE, Tell GS. Intake of vitamin K1 and K2 and risk of hip fractures: The Hordaland Health Study. Bone 2011; 49: 990995.

17 Booth SL, Broe KE, Gagnon DR, et al. Vitamin K intake and bone mineral density in women and men. Am J Clin Nutr 2003; 77: 512-516.

18 Katsuyama H, Otsuki T, Tomita M, et al. Menaquinone-7 regulates the expressions of osteocalcin, OPG, RANKL and RANK in osteoblastic MC3T3E1 cells. Int J Mol Med 2005; 15: 231-236.

19 Sasaki N, Kusano E, Takahashi H, et al. Vitamin K2 inhibits glucocorticoidinduced bone loss partly by preventing the reduction of osteoprotegerin (OPG). J Bone Miner Metab 2005; 23: 41-47.

20 Morishita M, Nagashima M, Wauke K, Takahashi H, Takenouchi K. Osteoclast inhibitory effects of vitamin $\mathrm{K} 2$ alone or in combination with etidronate or risedronate in patients with rheumatoid arthritis: 2-year results. $J$ Rheumatol 2008; 35: 407-413.

21 Parekh PI, Petro AE, Tiller JM, Feinglos MN, Surwit RS. Reversal of dietinduced obesity and diabetes in C57BL/6J mice. Metabolism 1998; 47: 10891096.

22 Martín-Badosa E, Amblard D, Nuzzo S, Elmoutaouakkil A, Vico L, Peyrin F. Excised bone structures in mice: imaging at three-dimensional synchrotron radiation micro CT. Radiology 2003; 229: 921-928.

23 Fujikawa T, Sakurai T, Kashima I. Effects of a supplement containing vitamin K2 (MK7) and calcium phosphate (salmon bone powder) on the femur trabecular structure in ovariectomized mice: a study using threedimensional imaging analysis. Oral Radiology 2004; 20: 37-43.

24 Shiraki M, Shiraki Y, Aoki C, Miura M. Vitamin K2 (menatetrenone) effectively prevents fractures and sustains lumbar bone mineral density in osteoporosis. J Bone Miner Res 2000; 15: 515-521.

25 Iwamoto I, Kosha S, Noguchi S, et al. A longitudinal study of the effect of vitamin $\mathrm{K} 2$ on bone mineral density in postmenopausal women a comparative study with vitamin D3 and estrogen-progestin therapy. Maturitas 1999; 31: 161-164. 
26 Young HE, Mancini ML, Wright RP, et al. Mesenchymal stem cells reside within the connective tissues of many organs. Dev Dyn 1995; 202: 137-144.

27 Kim MS, Lee HA, Kim OJ, Sohn CM. Relationship between of bone morphological microstructure and inflammatory markers in growing mice fed on a high fat diet. Korean J Nutr 2011; 44: 481-487.

28 Brown JP, Delmas PD, Malaval L, Edouard C, Chapuy MC, Meunier PJ. Serum bone Gla-protein: a specific marker for bone formation in postmenopausal osteoporosis. Lancet 1984; 1: 1091-1093.

29 Patsch JM, Kiefer FW, Varga P, et al. Increased bone resorption and impaired bone microarchitecture in short-term and extended high-fat dietinduced obesity. Metabolism 2011; 60: 243-249.
30 Khosla S, Arrighi HM, Melton LJ 3rd, et al. Correlates of osteoprotegerin levels in women and men. Osteoporos Int 2002; 13: 394-399.

31 Simonet WS, Lacey DL, Dunstan CR, et al. Osteoprotegerin: a novel secreted protein involved in the regulation of bone density. Cell 1997; 89: 309-319.

32 Kim M, Kim H, Sohn C. Relationship between vitamin K status, bone mineral density, and hs-CRP in young Korean women. Nutr Res Pract 2010; 4: 507 514.

33 Yamaguchi M, Taguchi H, Gao YH, Igarashi A, Tsukamoto Y. Effect of vitamin K2 (menaquinone-7) in fermented soybean (natto) on bone loss in ovariectomized rats. J Bone Miner Metab 1999; 17: 23-29. 